\title{
Cost-effectiveness of two long-lasting insecticidal nets delivery models in mass campaign in rural Mozambique
}

\author{
Jorge A. H. Arroz ${ }^{{ }^{*}}$ (D), Baltazar Candrinho² ${ }^{4}$ Chandana Mendis ${ }^{1}$, Melanie Lopez ${ }^{3}$ and Maria do \\ Rosário O. Martins ${ }^{4}$
}

\begin{abstract}
Objective: The aim is to compare the cost-effectiveness of two long-lasting insecticidal nets (LLINs) delivery models (standard vs. new) in universal coverage (UC) campaigns in rural Mozambique.

Results: The total financial cost of delivering LLINs was US\$231,237.30 and US\$174,790.14 in the intervention (302,648 LLINs were delivered) and control districts (219,613 LLINs were delivered), respectively. The average costeffectiveness ratio (ACER) per LLIN delivered and ACER per household $(H H)$ achieving UC was lower in the intervention districts. The incremental cost-effectiveness ratio (ICER) per LLIN and ICER per HH reaching UC were US\$ 0.68 and US\$2.24, respectively. Both incremental net benefit (for delivered LLIN and for HHs reaching UC) were positive (intervention deemed cost-effective). Overall, the newer delivery model was the more cost-effective intervention. However, the long-term sustainability of either delivery models is far from guaranteed in Mozambique's current economic context.
\end{abstract}

Keywords: Long-lasting insecticidal nets campaign, Universal health coverage, New and standard delivery model, Cost-effectiveness analysis, Malaria, Mozambique

\section{Introduction}

Using long-lasting insecticidal nets (LLINs) can reduce malaria morbidity and mortality [1-3]. Worldwide funding for malaria control fell by $8 \%$ between 2013 and 2014 [4]. Funding for the provision of LLINs can continue to decrease [5] and it is necessary to ensure cost-effective and sustainable LLINs delivery models.

Spending on malaria control commodities is estimated to have increased globally from about US\$ 40 million in 2004 to about US\$ 1.6 billion in 2014, where LLINs were responsible for $63 \%$ of total spending in 2014 (US\$ 1 billion) [5]. Due to high burden of malaria in the sub Saharan Africa and the strategy of universal LLINs coverage, most of the international funding in 2014 was spent in the WHO African Region. In Mozambique, half of the

\footnotetext{
*Correspondence: jorge_arroz@wvi.org

${ }^{1}$ World Vision International, Maputo, Mozambique

Full list of author information is available at the end of the article
}

international funding for malaria intervention went to mosquito nets [5].

Most of the economic studies do not compare the distribution of LLINs through the same mechanisms or channel. Recently, Ntuku et al. [6] evaluated a fixed delivery strategy and a door-to-door strategy. Their findings show that the fixed delivery strategy achieved a higher LLIN coverage at lower delivery cost compared with the door-to-door strategy.

In 2015, Mozambique piloted a new model of LLIN delivery in campaign [7]. Two rural districts were intervened with a new LLIN delivery model, and two served as the control, maintaining the standard delivery model. Results of this pilot showed that $87.8 \%(302,648)$ of planned LLINs were distributed in the intervention districts compared to $77.1 \%(219,613)$ in the control districts [7].

The objective of this research is to compare the cost-effectiveness of the two delivery models in mass 
campaigns in rural Mozambique, and establish the most cost-effective LLIN delivery model.

\section{Main text \\ Methods \\ Setting and location}

The study was conducted in four rural districts of Mozambique. Two districts served as intervention (with the new delivery model); and two served as control (with standard delivery model). These districts were selected based on pragmatic criteria described elsewhere [7]. All four districts are rural, with limited access to health services, and low health, social and economic indicators $[7$, 8].

\section{Study design}

An observational and cross-sectional study with costeffectiveness analysis component was carried out using secondary data from the pilot study conducted between October and December 2015 [7].

\section{Collection of cost data}

The campaign costs were retrospectively collected from the providers' perspective. The costs considered were related to training of personnel, allowances, LLINs warehouse storage, LLIN transportation vehicles rental, and materials production (pamphlets, coupons, stickers, etc.).

These costs were aggregated into four categories: (1) micro-planning; (2) LLIN storage; (3) LLIN transport; (4) mobilization and training at district level, household registration, and LLIN distribution.

Costs were collected in local currency and United States Dollars (US\$). In 2015, the exchange rate was: 1 US $\$=42.00$ Meticais. No adjustment for inflation was undertaken since all cost were paid in 2015. No discount rate was applied since the temporal universe of analysis did not exceed 1 year.

\section{Comparators: the two delivery models}

Both delivery models are community-based. One delivery model allocates LLINs based on the assumption of one LLINs for every two persons in a household (intervention districts), and another the number of LLINs is allocated based on assumptions around households members sleeping patterns (control districts). A comprehensive description of the models and pitfalls associated during implementation are reported elsewhere $[7,8]$.

\section{Measurement of effectiveness}

Two endpoints were used to measure the effects of the campaign in the intervention and control districts: (i) number of LLINs delivered; (ii) households (HHs) achieving universal coverage (UC) target (one LLIN for every two persons). The number of HHs achieving UC was estimated according to the following steps:

- Step 1: percentage of $\mathrm{HHs}$ achieving UC-[70.8\% (95\% CI 67.6-74.0) in the intervention districts, and 59.6\% (95\% CI 56.2-63.0) in the control districts] [8];

- Step 2: registered HHs multiplied the step 1 results (136,985 HHs were registered in the intervention districts, and 120,246 HHs were registered in the control districts [7]).

\section{Cost-effectiveness analyses}

The following cost-effectiveness measures were calculated: (i) average cost-effectiveness ratio (ACER) per LLIN delivery; (ii) ACER per $\mathrm{HH}$ achieving UC; (iii) incremental cost-effectiveness ratio (ICER); and (iv) incremental net benefit (INB).

- The ACER per LLIN delivered and ACER per HH achieving UC was calculated by dividing the total implementation cost by the number of LLINs delivered and number of $\mathrm{HHs}$ achieving $\mathrm{UC}$, respectively.

- The ICER was calculated by dividing the difference between the total cost by the difference of effects in the intervention and control districts.

- The INB was calculated by valuing additional effect $(\triangle \mathrm{E})$ in dollars and then subtracting the associated additional cost $(\Delta C): \operatorname{INB}=(\Delta \mathrm{E} \times \lambda)-\Delta \mathrm{C}$, where $\lambda$ is willingness to pay (WTP) for a 1-unit gain of effect [9].

\section{Willingness to pay (WTP) and decision rule on cost-effectiveness \\ Three WTP was adopted:}

- WTP 1) for LLINs delivered (US\$ 1.32 per LLINadopted by the Global Fund for Mozambique incountry mass free campaign budget planning [10]);

- WTP 2) for LLINs delivered plus LLIN purchases cost (US\$ 9.12 per LLIN - US\$ 1.32 + US\$ 7.8 which was the maximum inter-quartile purchase cost for the period 2005-2012 [11]); and

- WTP 3) for HHs achieving UC (US\$ 3.30 per household). This third WTP was determined by multiplying the average number of $\mathrm{HH}$ members (five) [7] by US\$ 1.32, and dividing by two (one LLIN for every two persons).

The cost-effectiveness decision rule was based on INB results. Two INB was calculated: INB for delivered LLIN (using WTP 1 and 2) and INB for HHs achieving UC 
(using WTP 3). A positive INB means that the new intervention extra benefits $(\Delta \mathrm{E} \times \lambda)$ outweighs its extra costs $(\Delta C)$, i.e., the new intervention is deemed cost-effective. Conversely, when INB is less than 0 (negative INB), the new intervention is not cost-effective [9].

\section{Sensitivity analysis}

A one-way sensitivity analysis was performed on the following parameters and assumptions: (i) free warehouses; (ii) transport cost $( \pm 50 \%)$; and (iii) costs of LLINs purchase $(-25 \%,-50 \%)$. Base case cost analysis was used to calculate the percentage of deviation. For the first two parameters, the base case was the ACER and ICER per LLIN delivered. For the third parameter, the base case was also ACER and ICER per LLIN delivered but also included the 2014 purchase cost of US\$ 3.63 per LLIN for the planned 344,770 LLINs in the intervention and 284,873 LLINs in the control districts.

The US\$ 3.63 per LLIN was based on the unit cost for Disease Control Technologies Royal Sentry ${ }^{\circledR}$ rectangular LLINs $190 \times 180 \times 180 \mathrm{~cm}$ of US\$ 3.19; procurement fee 1.50\%; outbound transport charges $11.94 \%$; transport insurance charges $0.14 \%$; question and answer charges $0.09 \%$; and pre-shipment inspection charges $0.12 \%$.

\section{Results}

\section{Financial costs of the LLIN campaign}

The total financial cost of the campaign from the providers' perspective was US\$231,237.30 and US\$ $174,790.14$ in the intervention and the control districts, respectively. Cost activity category 4 and 3 comprised around $43 \%$ and $38 \%$ in the intervention districts and $50 \%$ and $41 \%$ in the control districts, respectively. Cost activity category 4 were US\$ 0.06/LLIN higher in the control districts. The ACER per LLIN delivered was US\$ 0.76 and US\$ 0.80 in the intervention and control districts, respectively-Table 1 . The ACER for HHs achieving UC was lower in the intervention districts (US\$ 2.38 vs. US\$ 2.43)-Table 2.

\section{Cost-effectiveness and decision rule}

The overall ICER to deliver one additional LLIN was US\$ 0.68 , with a positive INB (intervention deemed costeffective), i.e., a saving of more than US $\$ 50,000$ per LLIN delivered would result from switching from the standard to new delivery model (with U\$S 1.32 as WTP)-Table 2. The overall ICER for one households reaching universal coverage was US\$ 2.24 , with a positive INB, i.e., a saving of more than US\$26,000 per household reaching universal coverage would result from switching from the standard to new delivery model (with U\$S 3.30 as WTP)-Table 2.

\section{Sensitivity analysis}

After a sensitivity analysis, the ACER per LLIN delivered remained at a lower rate (less sensitive) in the intervention districts rather than in the control districts, i.e., the results of ACER per LLIN delivered remain robust.

Table 1 Total cost and cost per LLIN delivered (US\$) for each category in the intervention and control districts

\begin{tabular}{|c|c|c|c|c|}
\hline \multirow[b]{2}{*}{ LLIN delivered } & \multicolumn{2}{|c|}{ Intervention (new delivery model) } & \multicolumn{2}{|c|}{ Control (standard delivery model) } \\
\hline & 302,648 & & 219,613 & \\
\hline Aggregated and standardized categories & Cost & $\%$ & Cost & $\%$ \\
\hline 1. Micro-planning & 6184.85 & 2.7 & 5580.84 & 3.2 \\
\hline ACER per LLIN delivered & 0.02 & & 0.03 & \\
\hline 2. LLIN warehouse storage & 6983.76 & 3.0 & 6880.33 & 3.9 \\
\hline ACER per LLIN delivered & 0.02 & & 0.03 & \\
\hline 3. LLIN transport & $86,908.64$ & 37.6 & $71,007.48$ & 40.6 \\
\hline ACER per LLIN delivered & 0.29 & & 0.32 & \\
\hline $\begin{array}{l}\text { 4. Mobilization, trainings at district level, } \\
\text { household registration, and LLIN distribution }\end{array}$ & $99,105.53$ & 42.9 & $86,736.97$ & 49.6 \\
\hline ACER per LLIN delivered & 0.33 & & 0.39 & \\
\hline 4.1 Coupons and Stickers production & $32,054.52$ & 13.9 & NA & NA \\
\hline ACER per LLIN delivered & 0.11 & & NA & \\
\hline 4.2 Household registration data analysis & NA & NA & 4584.52 & 2.6 \\
\hline ACER per LLIN delivered & NA & & 0.02 & \\
\hline Total cost & $231,237.30$ & 100.0 & $174,790.14$ & 100.0 \\
\hline ACER per LLIN delivered & 0.76 & & 0.80 & \\
\hline
\end{tabular}


Table 2 Comparative cost-effectiveness results in the intervention and control districts

\begin{tabular}{|c|c|c|}
\hline Effects and cost-effectiveness indicators & Intervention (new delivery model) & $\begin{array}{l}\text { Control } \\
\text { (standard } \\
\text { delivery model) }\end{array}$ \\
\hline Delivered LLINs & 302,648 & 219,613 \\
\hline Registered Households & 136,985 & 120,446 \\
\hline HHs achieving UC (\%) & 70.8 & 59.6 \\
\hline HHs with UC & 96,985 & 71,786 \\
\hline Total cost (U\$S) & $231,237.30$ & $174,790.14$ \\
\hline ACER for HHs achieving UC (U\$S) & 2.38 & 2.43 \\
\hline$\Delta$ Cost (U\$S) & $56,447.16$ & \\
\hline$\Delta$ Effect (LLINs delivered) & 83,035 & \\
\hline$\triangle$ Effect (HHs achieving UC) & 25,199 & \\
\hline ICER for delivered LLIN (U\$S) & 0.68 & \\
\hline ICER for HHs achieving UC (U\$S) & 2.24 & \\
\hline INB for delivered LLIN (U\$S) & $+53,159.04$ & \\
\hline INB for HHs achieving UC (U\$S) & $+26,709.54$ & \\
\hline
\end{tabular}

The cost-effectiveness of the new delivery model also remained sustained for all the parameters tested (positive INB even using WTP 2)-Table 3.

\section{Discussion}

This cost-effectiveness study demonstrates that the new delivery model is the more cost-effective strategy for the universal coverage campaign. The positive incremental net benefit shows that important savings could be achieved from adopting the new delivery model (opportunity-cost).

The ACER per LLIN delivered was lower in the intervention districts. This was mainly driven by the low relative contribution of the micro-planning, LLINs transport, and district-level activities costs. The ACER per $\mathrm{HH}$ achieving UC was also lower in the intervention district.

Paintain et al. [12] found higher financial costs for the distribution of LLINs-US\$ 1.19 (ranging from US\$ 1.08 to US\$1.41). However, Grabowsky et al. [13] found financial costs of around US $\$ 0.32$, which is considerably lower than what was found in the present study. As for Mueller et al.s [14], they incurred an ACER of US\$ 1.6/LLIN. This ACER is higher than what was found in this study, for either the new or standard delivery model.

From a health-financing point of view, the high overall cost found for these interventions casts doubt on

Table 3 Deterministic one-way sensitivity analysis of cost estimates to key assumptions

\begin{tabular}{|c|c|c|c|c|c|c|c|}
\hline Parameter tested & $\begin{array}{l}\text { Control/ } \\
\text { intervention } \\
\text { districts }\end{array}$ & Cost (US\$) & ACER $_{\text {LLIN }}$ & $\begin{array}{l}\% \text { ACER }_{\text {LLIN }} \\
\text { deviation }\end{array}$ & ICER $_{\text {LLIN }}$ & $\begin{array}{l}\% \text { ICER }_{\text {LIN }} \\
\text { deviation }\end{array}$ & $\mathrm{INB}_{\text {LLIN }}$ \\
\hline \multirow[t]{2}{*}{ Free warehouse } & Control & $167,909.81$ & 0.76 & -4.43 & & & \\
\hline & Intervention & $224,253.54$ & 0.74 & -2.50 & 0.68 & -0.18 & $53,262.46$ \\
\hline \multirow[t]{2}{*}{ Transport cost $(+50 \%)$} & Control & $210,293.88$ & 0.96 & 19.70 & & & \\
\hline & Intervention & $274,691.63$ & 0.91 & 19.42 & 0.78 & 14.09 & $45,208.45$ \\
\hline \multirow[t]{2}{*}{ Transport cost $(-50 \%)$} & Control & $139,286.40$ & 0.63 & -20.72 & & & \\
\hline & Intervention & $187,782.98$ & 0.62 & -18.36 & 0.58 & -14.08 & $61,109.62$ \\
\hline \multirow[t]{2}{*}{ LLIN purchase cost + delivery cost } & Control & $1,214,576.59$ & 5.53 & NA & & & \\
\hline & Intervention & $1,489,647.80$ & 4.92 & NA & 3.31 & NA & $482,207.98$ \\
\hline \multirow[t]{2}{*}{ Less $25 \%$ LLIN purchase cost + delivery cost } & Control & $954,629.98$ & 4.35 & -21.39 & & & \\
\hline & Intervention & $1,175,045.18$ & 3.88 & -21.09 & 2.65 & -19.80 & $536,864.00$ \\
\hline \multirow[t]{2}{*}{ Less $50 \%$ LLIN purchase cost + delivery cost } & Control & $694,683.36$ & 3.16 & -42.80 & & & \\
\hline & Intervention & $860,442.55$ & 2.84 & -42.21 & 2.00 & -39.69 & $591,520.01$ \\
\hline
\end{tabular}

NA not applicable because is the new base case with the inclusion of LLIN purchase cost into delivery cost 
their long-term sustainability in low-income contexts. Mozambique allocated US\$ 580.9 million (9\% of the National budget) to the health sector in 2015 [15]. For an estimated 25,727,911 inhabitants in 2015 [16], this budget for the health sector corresponds to US\$ 22.6 per capita (assuming this as Mozambican State WTP). Taking into account the mean cost to distribute one LLIN with the new intervention (US\$ 0.76), and that one LLIN would benefit two persons, the financial sustainability of the intervention would be guaranteed if a campaign were taken stand-alone by the Mozambican State and the WTP were only for the malaria programme $(\mathrm{ICER}<\mathrm{WTP})$.

However, considering that the Ministry of Health does not focus exclusively on LLIN campaigns, and other health programmes requires budgetary allocation, the country would not be in a position to guarantee financial sustainability for LLIN distribution. The Mozambique health sector allocated US\$ 4,186,129 to the National Malaria Control Programme in 2014 [4]. Considering that $100 \%$ of the Mozambican population is at risk for malaria, this allocation corresponds to US\$ 0.16 per capita (WTP), i.e., US\$ 0.32 for each two persons (US\$ 0.44 less than the ACER per LLIN in the intervention). This WTP clearly demonstrates the current financial un-sustainability of the country in assuming the LLINs campaign. The same conclusion holds even considering free warehouse storage, less 50\% transport costs, and 50\% reduction of LLINs' purchase cost.

Bed nets campaign is still more cost-effective than indoor residual spraying (US\$ 5.41 per person protected) [17], RTS,S (US\$ 39.25 per fully vaccinated child) [18, 19], and treatment (US\$2.59 per person tested and treated) [20]. This is in line with what Winskill et al. [3] found in their modelling cost-effectiveness study. In conclusion, the new delivery model is worthwhile (INB positive) from a programme provider perspective and current donor economic outlook. However, the long-term sustainability of either delivery models is far from guaranteed in Mozambique's current economic context.

\section{Limitations}

The WTP is often estimated through extensive surveys and is not always available [21]. The rationale for using the three ceiling is not only justifiable, but it is also appropriate to the country context. However, it is suggested that each country should adopt their own value for money ceiling, or make use of net benefit approach with cost-effectiveness acceptability curve if the ceiling is unknown plotting probability of cost-effectiveness against variation of the ceiling. Another limitation is the one-way sensitivity analyses. In the "real-world" more than one parameter varies at a time, and correlation between variation in multiple parameters can overstate uncertainty.

\section{Abbreviations}

ACER: average cost-effectiveness ratio; $\mathrm{HH} / \mathrm{HH}$ : household/households; ICER: incremental cost-effectiveness ratio; INB: incremental net benefit; LLIN/LLINs: long-lasting insecticidal net/long-lasting insecticidal nets; OR: odds ratio; SA: sensitivity analysis; UC: universal coverage; WTP: willingness-to-pay.

\section{Acknowledgements}

The authors would like to acknowledge the contributions of World Vision Mozambique and the Foundation for the Community Development for providing the financial records. The corresponding author would like to also acknowledge Prof. Giuliano Russo for encouragement and initiation in the field of health economics.

\section{Authors' contributions}

JAHA conceived and designed the protocol, performed data analysis, and wrote the manuscript. BC, ML and CM supported critical manuscript review. MROM supported the protocol design, data analysis, contributed to manuscript writing. All authors read and approved the final manuscript.

\section{Funding}

The LLIN universal coverage campaign in Mozambique was supported through a financial contribution of Global Fund to Fight AIDS, Tuberculosis, and Malaria. The Funding body did not have any role in the design of the study and collection, analysis, and interpretation of data and in writing the manuscript.

\section{Availability of data and materials}

The datasets used and/or analysed during the current study are available from the corresponding author, upon reasonable request.

\section{Ethics approval and consent to participate}

The study was administratively authorized by the Provincial Health Departments of Zambezia (Ref 2270/DPSZ/512/2015) and Manica (09/11/2015), and also received authorization from the National Committee on Bioethics in Health (Ref 112/CNBS/2015).

\section{Consent to publish}

Not applicable.

\section{Competing interests}

The authors declare that they have no competing interests.

\section{Author details}

${ }^{1}$ World Vision International, Maputo, Mozambique. ${ }^{2}$ National Malaria Control Programme, Maputo, Mozambique. ${ }^{3}$ World Vision Inc., Federal Way, WA, USA.

${ }^{4}$ Global Health and Tropical Medicine, GHTM, Instituto de Higiene e Medicina Tropical, IHMT, Universidade Nova de Lisboa, UNL, Rua da Junqueira 100,

1349-008 Lisbon, Portugal.

Received: 27 July 2019 Accepted: 7 September 2019

Published online: 14 September 2019

\section{References}

1. Bennett A, Smith SJ, Yambasu S, Jambai A, Alemu W, Kabano A, et al. Household ownership and use of insecticide-treated mosquito nets in Sierra Leone 6 months after a national mass-distribution campaign. PLoS ONE. 2012;7:e37927.

2. Walker PGT, Griffin JT, Ferguson NM, Ghani AC. Estimating the most efficient allocation of interventions to achieve reductions in Plasmodium falciparum malaria burden and transmission in Africa: a modelling study. Lancet Glob Health. 2016;4:e474-84.

3. Winskill P, Walker PGT, Griffin JT, Ghani AC. Modeling the cost effectiveness of introducing the RTS,S malaria vaccine relative to scaling up 
other malaria interventions in sub-Saharan Africa. BMJ Glob Health. 2017;2(1):e000090.

4. WHO Global Malaria Programme. World malaria report. Geneva:WHO 2015. http://www.who.int/malaria/publications/world-malaria-repor t-2015/en/. Accessed 20 May 2017.

5. WHO Global Malaria Programme. World malaria report. Geneva: WHO; 2012. http://www.who.int/malaria/publications/world_malaria_repor t_2012/report/en/. Accessed 20 May 2017.

6. Ntuku HM, Ruckstuhl L, Julo-Réminiac J-E, Umesumbu SE, Bokota A, Tshefu AK, et al. Long-lasting insecticidal net (LLIN) ownership, use and cost of implementation after a mass distribution campaign in Kasaï Occidental Province, Democratic Republic of Congo. Malaria J. 2017;16:22.

7. Arroz J, Mendis C, Pinto L, Candrinho B, Pinto J, Martins MRO. Implementation strategies to increase access and demand of long-lasting insecticidal nets: a before-and-after study and scale-up process in Mozambique. Malaria J. 2017:16:429.

8. Arroz J, Candrinho B, Mendis C, Varela P, Pinto J, Martins MRO. Effectiveness of a new long lasting insecticidal nets delivery model in two rural districts of Mozambique: a before-after study. Malaria J. 2018;17:66.

9. Hoch JS, Dewa CS. A clinician's guide to correct cost-effectiveness analysis: think incremental not average. Can J Psychiatry. 2008;4(53):267-74.

10. MISAU and WVM. Adenda ao Memorando de Entendimento entre o Ministério da Saúde da República de Moçambique e a Organização Não Governamental Visão Mundial Moçambique. 2017 (Unpublished).

11. Wafula F, Agweyu A, Macintyre K. Regional and temporal trends in malaria commodity costs: an analysis of Global Fund data for 79 countries. Malaria J. 2013;12:466

12. Paintain LS, Awini E, Addei S, Kukula V, Nikoi C, Sarpong D, et al. Evaluation of a universal long-lasting insecticidal net (LLIN) distribution campaign in Ghana: cost effectiveness of distribution and hang-up activities. Malaria J. 2014;13:71.

13. Grabowsky M, Nobiya T, Ahun M, Donna R, Lengor M, Zimmerman $D$, et al. Distributing insecticide-treated bed nets during measles vaccination: a low-cost means of achieving high and equitable coverage. Bull World Health Organ. 2005;83:3.

14. Mueller DH, Wiseman V, Bakusa D, Morgah K, Daré A, Tchamdja P. Costeffectiveness analysis of insecticide-treated net distribution as part of the Togo Integrated Child Health Campaign. Malaria J. 2008;7:73.

15. UNICEF. Informe Orçamental 2015: Saúde. http://budget.unicef.org.mz/ informes/2015UNICEF_BB2015_Saude.pdf. Accessed 20 May 2017.

16. Instituto Nacional de Estatística. III Recenseamento Geral da População e Habitação 2007. Moçambique; 2007. http://www.ine.gov.mz/estatistic as/estatisticas-demograficas-e-indicadores-sociais/projeccoes-da-popul acao. Accessed 20 May 2017.

17. PMI. President's malaria initiative africa indoor residual spraying project. 2012. http://www.africairs.net/. Accessed 7 Sept 2017.

18. Penny MA, Verity R, Bever CA, Sauboin C, Galactionova K, Flasche S, et al. Public health impact and cost-effectiveness of the RTS,S/AS01 malaria vaccine: a systematic comparison of predictions from four mathematical models. Lancet. 2016;387:367-75.

19. Galactionova K, Bertram M, Lauer J, Tediosi F. Costing RTS,S introduction in Burkina Faso, Ghana, Kenya, Senegal, Tanzania, and Uganda: a generalizable approach drawing on publicly available data. Vaccine. 2015;33:6710-8.

20. Okell LC, Cairns M, Griffin JT, Ferguson NM, Tarning J, Jagoe G, et al. Contrasting benefits of different artemisinin combination therapies as firstline malaria treatments using model-based cost-effectiveness analysis. Nat Commun. 2014;5:5606.

21. Hounton S, Newlands D. Applying the net-benefit framework for assessing cost-effectiveness of interventions towards universal health coverage. Cost Eff Resour Alloc. 2012;10:8.

\section{Publisher's Note}

Springer Nature remains neutral with regard to jurisdictional claims in published maps and institutional affiliations.
Ready to submit your research? Choose BMC and benefit from:

- fast, convenient online submission

- thorough peer review by experienced researchers in your field

- rapid publication on acceptance

- support for research data, including large and complex data types

- gold Open Access which fosters wider collaboration and increased citations

- maximum visibility for your research: over 100M website views per year

At BMC, research is always in progress.

Learn more biomedcentral.com/submissions 